\title{
Razón y locura en la antropología de Hegel
}

\author{
DANIEL BRAUER \\ Universidad de Buenos Aires / CONICET
}

"Sólo el hombre llega a captarse a sí mismo en aquella completa abstracción del
yo. Por ello tiene, por decirlo de alguna manera, el privilegio de la locura y la
demencia"

G. W. F. Hegel (1830) 1970, Agregado al § 408, p. 168

El tratamiento que Hegel lleva a cabo de la locura en el marco de la Enciclopedia depara una serie de sorpresas aún para los conocedores del sistema. En primer lugar, porque la importancia que el autor le atribuye al tema, no ha tenido una recepción equivalente en la exégesis de su obra, algo que comienza a revertirse recién en los últimos años (véase: D. Berthold-Bond, 1995). En segundo lugar, porque muchas de sus observaciones contrastan con el prejuicio de un edificio conceptual en el que no parece haber lugar para lo irracional e incompleto. En tercer lugar, porque la locura lejos de ser presentada como lo contrario de la razón es vista más bien como una posibilidad ineludiblemente vinculada a su propia naturaleza.

Esto resulta particularmente notorio por la desproporcionada extensión del $\S 408$ de la tercera edición de la Enciclopedia al que el editor Ludwig Boumann (1845) añadió un comentario (Zusatz) basado en diversos apuntes de los cursos. Tanto la desproporcionada amplitud como el contenido del Zusatz, sirven para testimoniar que el interés de Hegel por el tema no es algo secundario ni carece de originalidad, aún teniendo en cuenta el horizonte limitado del saber de su tiempo; sólo comparable con el también desproporcionado Zusatz al § 405 en el que Hegel se ocupa, entre otras cosas, del "magnetismo animal" (hipnotismo), que tanto fascinó a su generación y particularmente al Romanticismo (acerca de Mesmer véase: F. Rrausky, 1977).

Si bien puede considerarse que ya en el capítulo de la Fenomenología del Espíritu que trata acerca de "La ley del corazón y el desvarío de la vanidad" (G. W. F. Hegel, (1807) 1970, pp. 275-283) pueden reconocerse rasgos de lo que luego será su concepción de la locura, un tratamiento explícito aparece por 
primera vez en el breve $\$ 153$ de la llamada Propedéutica de la época de Nuremberg (G. W. F. Hegel, (1808) 1970, pp. 49-50) en el que puede encontrarse un esbozo de lo que será luego el sistema enciclopédico.

Ya en la primera edición de la Enciclopedia de 1817, Hegel dedica un extenso parágrafo al problema de la locura (G. W. F. Hegel, (1817) 1968, §321, pp. 239-242) que luego será modificado y ampliado en la edición de 1830.

Mientras que en el $\S 408$ de la Enciclopedia de Berlín sólo se cita la obra de Pinel (Ph. Pinel, 1801), con gran admiración por cierto (acerca de Pinel v.: W. Riese 1969), en los apuntes de las Lecciones sobre la Filosofía del Espíritu (G. W. F. Hegel, (1827-1828) 1994, pp. 110-123), publicadas recientemente (1994) por Franz Hespe y Burckhard Tuschling, queda documentada además la familiaridad con Esquirol y una serie de autores hoy poco conocidos, pero que en todo caso dan cuenta de múltiples lecturas (G. W. F. Hegel, (1827-1828) 1994, pp. 217-225, D. Berthold-Bond, 1995, pp.9-35).

A todo esto debe agregarse que Hegel mismo indica que la locura desempeña en esta sección del espíritu subjetivo un papel análogo al del delito en el caso del espíritu objetivo. Pero mientras que acerca de la teoría hegeliana del crimen y el castigo contamos con múltiples comentarios y discusiones, la bibliografía acerca de la locura en Hegel es aún muy reducida y reciente. La originalidad con que Hegel encara el tema ha obtenido un mayor reconocimiento por parte de una historiadora de la psiquiatría como Galdys Swain que por varios de los comentaristas de la Enciclopedia (compárese el texto de Swain (1994,pp.1-70) con su pobre recepción en I. Fetscher (1970, pp. 83-86) y adversa en H. Drue (2000, pp. 232-245).

Las razones de la preocupación de Hegel por la cuestión son varias. En primer lugar, entender la locura representa un desafío para la razón, más aún cuando se trata de un sistema que considera que lo "real" (wirklich) tiene una estructura "racional" (vernünftig). Encontrar la "lógica" de la locura parece sin embargo una empresa paradójica si no contradictoria.

En segundo lugar, si no puede negarse que la locura es de algún modo "real", su realidad parece marcar, más aún que la cosa-en-sí de Kant y por razones diferentes, los límites de la razón misma. Es necesario entonces para el proyecto de un racionalismo radical como el hegeliano asumir el desafío de establecer el modo de su funcionamiento, la razón de la sinrazón (véase sobre esto: D. Berthold-Bond 1995, pp. 37-44, que a mi juicio exagera al querer ver en Hegel un Freud avant la lettre).

En tercer lugar, el examen que Hegel lleva a cabo del tema forma parte también de su toma de posición frente al Romanticismo y su reivindicación del sueño y la locura como fuentes del "genio" creador - (acerca de la relación de Hegel con Hölderlin, su hermana Chistiane y los motivos personales que pueden haberlo conducido a ocuparse del tema, véase D. Berthold-Bond, 1995, 
pp. 54-64).

Ante todo, resulta interesante el lugar que ocupa el tratamiento de la locura en el marco del sistema enciclopédico. Este se encuentra en la primera parte del "Espíritu subjetivo" dedicado a la "Antropología" y más precisamente en la segunda sección que tiene por título "el alma sintiente" (die fühlende Seele). A su vez, el segundo capítulo es denominado "sentimiento de sî" (Selbsgefühl).

Mientras que en la primera sección del mismo que trata del "sentimiento en su inmediatez", el sujeto se encuentra en una unidad indiferenciada con su cuerpo, o mejor dicho es, en tanto "alma" esa unidad misma, y en la tercera, se ocupa de la "costumbre" (Gewonnheit), en la que se consuma el proceso de apropiación de la naturalidad de cuerpo, instinto y pasiones, el texto dedicado al "sentimiento de sî" (Selbstgefühl) describe el surgimiento de un cisma interior que caracteriza como "contradicción" (Widerspruch). Ahora bien, este paulatino proceso "reflexivo" de toma de distancia del sujeto de su propia situación corporal y biográfica no es, como veremos, algo específico de la enfermedad mental. Atañe a la propia naturaleza humana que se constituye como tal recién en la sección "conciencia", mientras que las secciones anteriores conciernen a disposiciones de un ser vivo (sensaciones, sueño-vigilia, sentimiento de sí, etc.) que el hombre comparte con los animales, aún cuando en él adquieran formas específicas. El tema central de este trabajo no es tanto el paradójico vínculo entre "locura" y razón en general sino la exploración de la relación entre locura y conciencia en la antropología hegeliana.

\section{I}

Antes de analizar los textos resultará útil diferenciar dos planos que en el discurso de la Enciclopedia aparecen fusionados y cuya no separación da lugar a malentendidos. Por un lado, el orden de la exposición y su articulación de acuerdo a un esquema sistemático, tal como puede comprobarse en el índice de la obra y que podemos calificar de "externo", aún cuando éste no es el modo en que el autor pretende presentarlo. Por el otro, lo que podemos llamar la dialéctica interna a los objetos tratados que conduce de uno a otro. El primer plano, que concierne al "lugar" de cada tema en el marco del "sistema del saber", nos da una serie de valiosas indicaciones acerca del sentido de las materias allí tratadas y su interrelación con otras. La dialéctica interna en cambio, que cabe calificar de "fenomenológica", nos muestra cómo la "cosa misma" en virtud de su dinámica propia remite a formas ontológicas más complejas. No siempre ambos planos coinciden en la exposición. En el primer caso, los temas son presentados de acuerdo a un esquema dialéctico más o menos rígido, mientras que en el segundo, nos enfrentamos a un pensamiento menos cerrado y en gestación. Esa distinción puede comprobarse con mayor claridad en la diferencia en el tratamiento que Hegel lleva a cabo de la Antropología (del mismo modo 
que luego de la Psicología) y de la Fenomenología en el contexto de la teoría del "espíritu subjetivo" de la Enciclopedia. Mientras que en los capítulos de la primera (y de la última) se pasa revista a diferentes dispositivos de la vida anímica de las funciones vitales de un individuo, en la segunda, los distintos capítulos, "certeza sensible", "percepción "y "entendimiento" constituyen "estadios" (Stufen) de la evolución de la conciencia misma - a diferencia del sueño, del sentimiento de sí, de la costumbre, etc. no puede decirse que constituyan "fases" en el mismo sentido de la formación de un sujeto, aunque impliquen una mayor complejidad, o en todo caso lo son desde la perspectiva externa del observador. En la segunda sección del "Espíritu subjetivo" Hegel parece atenerse, aunque no siempre, al punto de vista interior, "fenomenológico" de la conciencia, tal como fuera desarrollado en su gran obra anterior. El hecho que en la sección de la Enciclopedia dedicada a la "conciencia" esta perspectiva no sea abandonada del todo hace que los últimos capítulos de la Antropología resulten, como veremos, esclarecedores para la comprensión de la estructura de la conciencia misma.

De esta posición en el sistema pueden extraerse una serie de conclusiones. En primer lugar (1), la locura, tanto como su posible tratamiento, son considerados así desde un doble punto de vista, físico y mental que Hegel caracteriza como "psíquico" (psychisch) (G. W. F. Hegel (1830) 1970, p. 125).

En segundo lugar (2), que Hegel ubica la problemática de la locura en el plano de los sentimientos y emociones, o sea como una perturbación de la vida anímica emocional y no tanto intelectual (y en esto coincide con el enfoque de Pinel). Si el enfermo razona bien el problema es que parte de falsas creencias, de ahí que sea necesario, como suele decirse, "seguirle la corriente" con la intención de que perciba en algún momento la incoherencia de su pensamiento con otras representaciones también presentes en él.

En tercer lugar (3), la multiplicidad de emociones y sentimientos está puesta en relación con una unidad, con un foco central y centralizador que Hegel llama "sentimiento de sî", de modo que el individuo afectado por la locura dispone de alguna forma de percepción de sí mismo. Este eje es caracterizado ya en el $\S 407$ como un "uno subjetivo" (als subjektives Eins) (G. W. F. Hegel (1830) 1970, p. 160).

De la lectura de estos parágrafos surge en cuarto lugar (4), que Hegel concibe a la locura como la perturbación en mayor o menor grado de una función psíquica que aquí sólo es presupuesta pero no tratada. En efecto, con el nombre genérico de "locura" Hegel entiende una alteración no del "alma" sino de la "conciencia", facultad cuyo funcionamiento es expuesto recién en la sección siguiente dedicada a la "Fenomenología del Espíritu". De modo tal que el capítulo no sólo anticipa desarrollos que tendrán lugar después (p.161), sino que sus argumentos están ordenados teleológicamente en vista a ella (en esto 
D. Berthold-Bond 1995, pp. 71-93 cree reconocer un equivalente a la noción de "regresión" en Freud). Es precisamente la teoría dialéctica de la conciencia lo que diferencia estos textos de las hipótesis esbozadas por Pinel y la que le otorga un marco conceptual para pensar la perturbación mental.

Ya al comienzo del $\S 408$ se indica que constituye un rasgo esencial de la "totalidad viva en tanto individualidad despertar hacia el juicio en sî", o sea en el interior de sí misma. Sabemos que esta apelación a la categoría lógicaontológica de juicio con la que Hegel opera aquí indica un desdoblamiento interior que alcanza su realización plena en lo que llama "conciencia".

En la locura se mostrarían, por un lado, y curiosamente un estadio "necesario" (G. W. F. Hegel (1830) 1970, §408, p. 171) en la formación del espíritu humano, por el otro, elementos estructurales de la conciencia misma que Hegel presupone y no desarrolla en la sección dedicada a ella.

La radical dicotomía entre razón y locura que, según Foucault, caracterizaría el saber de la Ilustración no se encuentra en Hegel para quien la locura es un "privilegio" (véase la cita del epígrafe) de un ser racional (para una crítica a la tesis de Foucault véase M. Gauchet 1994, D. Bertohold-Bond 1994, pp.180-202 y el artículo de G. Lejeune 2009, contenido en este volumen). En todo caso, el tratamiento de la enfermedad mental anticipa la teoría hegeliana del yo y depende de ella. En efecto, la locura no es vista como un defecto de la racionalidad sino más bien de la conciencia.

Hegel entiende por "locura" (Verrücktheit) una serie muy amplia de patologías de diverso grado que corresponden sólo en parte a nuestra comprensión actual del fenómeno. Es cierto también, como sostiene Hermann Drüe, que la clasificación de las enfermedades mentales que propone el texto resulta obsoleta y es anterior a la de Kraepeling que sirve de base a las vigentes (Drue, 2000, p. 244). Pero por la misma razón lo es también la clasificación de Pinel mismo y la de todos los tratados de la época. Sin embargo, resulta interesante para nuestro tema que Hegel no se atiene a ella (véase: D. Berthold-Bond 1995, p.21).

Algunos rasgos de la concepción hegeliana de la locura resultan hoy particularmente notorios: (a) el mencionado enfoque psicosomático de la perturbación mental; (b) la consideración del individuo afectado como sujeto de derechos; (c) la visión de la locura como una enfermedad que no afecta a la totalidad del individuo sino a determinados aspectos de su vida consciente y que por lo tanto se lo debe tratar como un ser racional que convive con un trastorno, que en algunos casos puede ser pasajero y que a veces está en condiciones de reconocer, aunque más no fuera y ocasionalmente en forma retrospectiva el carácter justo o injusto de sus acciones; (d) el mostrarse partidario de un enfoque que Pinel denomina aún impropiamente "moral"( W. Riese 1969, pp.62-68) del paciente y que hoy asociamos a una terapia psicológica que apela ante todo a la capacidad de reflexión del sujeto mismo. Más aún, dado que para Hegel el "loco" no carece 
de la conciencia del bien y del mal, considera -algo que contrasta por cierto con la concepción actual- que debería ser considerado imputable por el resultado de sus actos y que, por lo tanto, sus transgresiones deberían ser castigadas de acuerdo a criterios de justicia que comparte en tanto portador de derechos (G.W. F. Hegel (1830) 1970, §408, Zusatz, p. 180). Por último, (e) llama la atención el modo en que el proceso de formación de la subjetividad propia es puesto en conexión directa con el establecimiento de relaciones intersubjetivas a lo largo de toda la sección en que se inscribe el capítulo.

"El verdadero tratamiento psíquico se atiene por lo tanto también al punto de vista de que la locura no es una pérdida abstracta de la razón, ni por el lado de la inteligencia ni por el de la voluntad y su imputabilidad, sino sólo locura, sólo [una] contradicción en la razón aún presente....” (G. W. F. Hegel (1830) 1970, $\S 408$, p. 162).

Ahora bien, si la locura presupone para Hegel a la "conciencia" y ella es caracterizada en general como una "contradicción" en el interior de la misma, ambas nociones deben ser aclaradas. En primer lugar, porque la palabra "contradicción" es utilizada aquí en el sentido propio de su filosofía. En segundo lugar, porque la "contradicción" así entendida, lejos de ser un defecto es aquello que define a la conciencia misma.

II

Cuando la conciencia "distingue algo de sí con lo que al mismo tiempo se relaciona", tal como es caracterizada en la Introducción a la Fenomenología del Espíritu (G. W. F. Hegel (1807) 1970, p. 76), ella es concebida con el modelo de la "identidad de la identidad y de la diferencia" con el que Hegel define a la contradicción misma (G. W. F. Hegel (1813) 1970, pp. 64-80). ¿En que consiste entonces la contradicción propia de la locura? Responder a esta pregunta resulta crucial tanto para la comprensión de la concepción hegeliana de la locura como de la conciencia. A lo que nos enfrentamos es a un uso equívoco de la noción de contradicción y a una compleja noción de conciencia que es necesario elucidar.

Lo que Hegel entiende por conciencia no es sólo un dispositivo cognitivo sino al mismo tiempo reflexivo. El ser de la conciencia consiste en el constante proceso mediante el cual el sujeto establece y modifica el modo en que se entiende a sí mismo en función de su visión de la realidad y su interacción con el mundo circundante material y social. La conciencia no está pensada en Hegel de acuerdo al modelo puntual de la mera percepción de un objeto intencional sino como un espacio denso de reflexión en el que las representaciones van siendo organizadas como parte de un "microcosmos" ordenado (G. W. F. Hegel (1830) 1970, §391, Zusatz, p. 51). La conciencia presupone un sujeto antropológico 
en el que se inscribe y que dispone de intuiciones, memoria, lenguaje, pensamiento, etc.. Temas que son tratados en el sistema enciclopédico ulteriormente en las secciones de la "Psicología", pero que no pueden sino presuponerse ya en ella. A la inversa, estas funciones son difíciles de concebir sin la presencia de alguna forma de conciencia.

Lo que en el marco del capítulo de la "Antropología" sobre "el sentimiento de sî", Hegel llama "genio" (Genius) (G. W. F. Hegel (1830) 1970, §405, p. 125), es presentado como un centro que da coherencia y unidad de acción a la vida anímica del individuo. La noción - que dicho sea de paso, ya aparecía mencionada en el capítulo que trata acerca de la relación intersubjetiva del feto con la madre - alude a un principio de dominación y regulación de las funciones corporales. Pero el hecho de que el Genius sea aquello que da coherencia y unidad a la multiplicidad de la vida sensitiva y emocional, a la vez que ejerce un "poder" (Macht) sobre ella, no significa que el individuo sea ya el sujeto de ese poder. Más aún, el individuo se hace sujeto propiamente dicho en la medida en que logra apropiarse de su propio Genius.

Más adelante y en una probable referencia a Descartes, Hegel habla del "genio maligno (böse Genius) del hombre que se vuelve dominante en la locura" (G. W. F. Hegel (1830) 1970, §408, p. 162).

Es que la diferencia entre este protosujeto de la vida anímica y el yo de la conciencia resulta decisiva. Mientras que el "genio" representa la simple identidad del individuo consigo como un centro de sentimientos y acción, con la aparición del "yo" de la conciencia el sujeto puede a la vez tomar distancia de sí y verse como uno más, como una posibilidad de la existencia humana. Lo que diferencia a ambos estadios es la universalidad vinculada al concepto del yo (Ich): en la conciencia el individuo mantiene una distancia consigo que por principio es insalvable a la vez que hace posible sus identificaciones y experiencias.

\section{III}

Hegel caracteriza a la conciencia misma como una "contradicción" (Widerspruch) interna al sujeto entre dos componentes esenciales de su propia estructura que resultan inseparables como las dos caras de una moneda: lo que ella atribuye al mundo y lo que considera propio. El tercer elemento implícito en este dispositivo es precisamente el sujeto que lleva a cabo la comparación entre ambos aspectos en el marco de su propia interioridad. Vemos así que el sujeto propiamente dicho aparece descentrado con respecto a sí mismo, ya que el yo es "un lado de la relación y toda la relación..." (G. W. F. Hegel (1830) $1970, \S 413$, p. 199). Se trata de una diferenciación importante: la expresión "yo" se refiere tanto a aquello que el sujeto identifica consigo y se atribuye, como al sujeto mismo que es consciente de ello. La conciencia es definida precisamente 
como una facultad que contrasta permanentemente su saber de sí con el modo en que le aparece el mundo y ella misma en él. Toda conciencia por elemental que fuese dispone de la creencia en la posibilidad de equivocarse. El proceso de aprendizaje y la reflexión en general no serían posibles si el sujeto no contase con esta posibilidad. Lo que parece fallar en el enfermo son los mecanismos para contrastar las propias creencias.

Sostener que el "loco" confunde las imágenes de su fantasía con sus representaciones de la realidad puede parecer una perogrullada si esta caracterización no se contextualiza en el marco de una teoría de la conciencia, para la cual no hay un mundo ajeno a ella al que se tuviese un acceso precategorial. La contrastación y revisión de representaciones forman parte de una actividad reflexiva esencial al sujeto, pero el examen tiene lugar "en el interior de sí misma" (G. W. F. Hegel (1807) 1970, p. 77), ya que éste no puede salirse de su propio aparato conceptual.

Dado que el examen de lo que el sujeto entiende por verdadero es presentado como un proceso inmanente a la conciencia, ésta parece estar concebida desde el principio como instalada en su entorno vital y el problema de la realidad del mundo exterior ni siquiera requiere ser planteado. Por otra parte, el mundo interior de la mente en el que el enfermo se encierra, ya se presenta permeado en sus imágenes por una interacción con el mundo y con los otros y no parece poder explicarse sin ella. Por el contrario, esta noción de sí coexiste aunque más no fuera mínimamente con cierta percepción del entorno espacio-temporal circundante. De ahí una "contradicción" permanente en la que la conciencia no logra integrar ambos polos y hacerlos formar parte de un "sistema" coherente.

Resulta significativo y a la vez consecuente que Hegel aproxime la locura a fenómenos cotidianos como la distracción, el error o el fanatismo religioso (G. W. F. Hegel (1830) 1970, §408,p. 161). También en ellos el individuo se encapsula en sí mismo y confunde sus representaciones subjetivas con la conciencia de su entorno. La locura es vista sí como un "soñar despierto" (p. 162).

A todo esto debe agregarse la descripción de la conciencia como un proceso dinámico, como algo esencialmente temporal (sobre la relación entre el yo y el tiempo véase D. Brauer 1982, pp. 152-155), frente a lo cual toda representación inmutable, "fija", se presenta como algo enfermizo.

Hegel se refiere al sujeto "sano" (gesund) y "cuerdo" (besonnen) como disponiendo en la "conciencia presente" (präsente Bewußtsein) de la totalidad ordenada de su mundo individual (geordneten Totalität seiner individuellen Welt)..." (G. W. F. Hegel (1830) 1970, §408, pp. 161-162).

Lo que de acuerdo a esto tendría lugar en las diferentes formas de "locura" (Verrücktheit) es, ya sea la separación de ambos polos constitutivos de la conciencia (conciencia de sí y conciencia del mundo), ya sea la fijación o iden- 
tificación del sujeto con una de sus posibilidades (imaginarias o parcialmente reales). En ambos casos la "certeza de sí" no es puesta a prueba mediante su confrontación y coherencia con el mundo. La escisión interior que define al campo de la conciencia se vuelve un abismo para el mismo sujeto que no puede ser cruzado de modo que ambos extremos se independizan. La conciencia ya no logra reconducir sus representaciones a la "idealidad" (Idealität) de una unidad coherente.

De ahí que las diferentes formas de tratamiento de la locura que aparecen mencionadas en el texto tengan por objetivo volver fluidas las representaciones del sujeto y reconducirlo nuevamente al mundo compartido. Pero es principalmente la recepción de las ideas de Pinel acerca del carácter terapéutico del trabajo lo que encuentra un suelo fructífero en una filosofía para la cual éste es constitutivo de la formación de la conciencia misma y la superación de la mera condición biológica. En el proceso de trabajo - como reza el célebre dictum del capítulo sobre la dialéctica amo/esclavo de la Fenomenología -, la conciencia "adviene a si misma (kommt es zu sich selbst)" (G. W. F. Hegel (1807) 1970, p. 152).

A diferencia de lo que sucede con el ego puntual del cogito cartesiano, Hegel nos presenta un sujeto complejo que no puede separarse de la conciencia concebida como un "sistema de mundo individual" (individuelles Weltsystem) (G. W. F. Hegel (1830) 1970, §408, p. 161) en el que una representación forma parte de un "todo ordenado" (geornete Totalität) (p. 162), inseparable de su cuerpo, su sexualidad, sus prójimos y su pertenencia a instituciones sociales.

La contradicción interior a la conciencia, usualmente presentada por Hegel en las diversas formas que asume como un factor dinámico y formador del sujeto, conduce aquí en su fijación rígida a su propia destrucción. Es que Hegel no entiende al yo como un mero sujeto cognitivo ni como un mero sujeto del deseo, sino a vez como ejerciendo un "poder" (Macht) que administra sus contenidos mentales y la multiplicidad de sus representaciones.

La "contradicción" que tiene lugar en la locura podría describirse entonces como una contradicción de la contradicción que define a la conciencia misma y que adopta diversas modalidades.

Es presuponiendo esta estructura que Hegel puede dar cuenta de fenómenos patológicos como la "idea fija" en la que el sujeto se vuelve víctima de una representación de la que no puede abstraerse e integrar en una imagen coherente el mundo que le toca vivir o, como sucede en el caso de la doble personalidad (G. W. F. Hegel (1830) 1970, §408, pp. 165) - tema recurrente en la literatura de la época - en la que el individuo identifica instancias y circunstancias de su propia vida psíquica con la presencia simultánea de dos sujetos diferentes e independientes en su propio interior.

Lo que en conformidad con esta visión tiene lugar en la perturbación 
mental en mayor o menor grado puede caracterizarse por tres rasgos esenciales. En primer lugar (1), por la falta de lo que Hegel llama "idealidad", es decir, la reconducción de la multiplicidad de la vida anímica a una totalidad coherente. En segundo lugar (2), por lo que en la versión de la Enciclopedia de 1817 llama: "La absoluta infelicidad de la contradicción" ( G. W. F. Hegel (1817) 1968, p.241. En efecto, el loco nunca lo es del todo y en él conviven su falsa conciencia (que Hegel llama aquí "subjetiva") con la conciencia que comparte intersubjetivamente (y que Hegel llama aquí "objetiva"). En tercer lugar (3), como ya se muestra también en la cita de más arriba, la enfermedad mental implica necesariamente un sufrimiento del que el sujeto no parece poder escapar por sí mismo.

Sin duda uno de los méritos del tratamiento que lleva a cabo Hegel del "sentimiento de si" consiste en el modo en que el proceso de formación de la subjetividad es puesto en una relación constitutiva con la intersubjetividad lo cual aparece ya en su visión de la relación de la madre con el feto, en la hipnosis, etc., y que luego culminará en el ámbito de lo práctico con la noción de "reconocimiento".

Es esta concepción dialógica y polémica de la conciencia consigo misma, que en el caso de la locura es llevada al extremo, lo que le permite a Hegel explorar otras formas de "alienación" social y política en las que el individuo no logra reconocerse a sí mismo.

Pensar la locura forma parte de una filosofía que ha intentado mostrar hasta el límite el alcance de la razón. Más allá de una etiología ligada al saber de su tiempo, sorprende la inteligibilidad con la que son presentados algunos de los mecanismos que conducen a la alienación mental. Pero también es cierto que, a pesar de la intención del autor, lo que se revela en estos textos para el lector contemporáneo, no es tanto la "necesidad" de la locura cuanto la contingencia y fragilidad de las condiciones de la razón misma.

\section{REFERENCIAS}

Berthold-Bond, D., 1995: Hegels Theory of Madness, Nueva York, State University of New York Press.

Brauer, D., 1982: Dialektik der Zeit. Untersuchungen zu Hegels Metaphysik der Weltgeschichte, Stuttgart-Bad-Cannstatt, Frommann-Holzboog.

Drüe, H. 2000, (editor con Annemarie Gethmann-Siefert, Christian Hackenesch, Walter Jaeschke. Wolfgang Neuser y Herbert Schnädelbach): Hegels 'Enzyklopadie der Philosophischen Wissenschaften'(1830). En Kommetar zum Systemgrundriss, Francfort del Meno, Suhrkamp.

Fetscher, I. 1970: Hegels Lehre vom Menschen, Stuttgart-Bad Cannstatt 1970 Gauchet, M.1994: “À la recherche d'une autre histoire de la folie”, en: Swain, G. 1994. 
Hegel, G. W. F. (1807) 1970: Werke in zwanzig Bänden, a cargo de Eva Moldenhauer y Karl-Marcus Michel, Tomo 3, Francfort del Meno, Suhrkamp. ,(1808-1817) 1970. Werke in zwanzig Bänden, a cargo de Eva Moldenhauer y Karl-Marcus Michel, Tomo 4, Francfort del Meno, Suhrkamp. , (1813) 1970. Werke in zwanzig Bänden, a cargo de Eva Moldenhauer y Karl-Marcus Michel, Tomo 6, Francfort del Meno, Suhrkamp , (1817) 1968: Enzyklopädie der philosophischen Wissenschaften im Grundrisse und andere Schriften aus der Heidelberger Zeit , tomo 6 de las Sämtliche Werke editadas por Hermann Glockner, Stuttgart. ,(1827-1828) 1994: Vorlesungen über die Philosophie des Geistes (Berlin 1827 /1828), editadas por Franz Hespe, Burckhard Tuschling y colaboradores, Hamburgo, Felix Meiner. , (1830) 1970: Werke in zwanzig Bänden, a cargo de Eva Moldenhauer y Karl-Marcus Michel, Tomo 10, Enzyklopädie der philosophischen Wissenschaften im Grundrisse, Francfort del Meno, Suhrkamp.

Lejeune, G. 2009 : « Hegel et Foucault. L'objectivité moderne de l'aliénation mentale et de son traitement », contenido en este volumen.

Pinel, Ph., 1801, Traité médico-philosophique sur l'alienation mentale, Paris.

Rausky, F., 1977:Mesmer ou la Revolution Therapeutique, Paris.

Riese, Walter, 1969: The Legacy of Pinel. An Inquiry into Thought on Mental Alienation, Nueva York.

Swain, G. 1994, "De Kant a Hegel: deux epoques de la folie", contenido ahora en su libro: Dialogue avec l'insensé. Essais d'histoire de la psiquiatrie précédé de À la recherche d'une autre histoire de la folie de Marcel Gauchet, Paris, Gallimard. 
